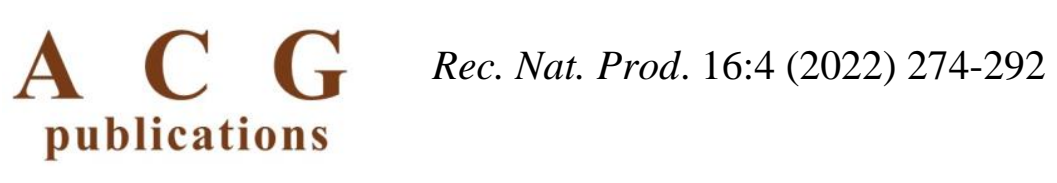

\title{
Current Techniques for the Search for Natural Products in
}

\section{Actinobacteria}

\author{
Janette Berenice González-Nava $\oplus^{\mathbf{1}}$, Scarlett Alonso-Carmona $\oplus^{\mathbf{1}}$, \\ Gauddy Lizeth Manzanares-Leal $\oplus^{1}$, Horacio Sandoval-Trujillo $\oplus^{2}$ \\ and Ninfa Ramírez Durán $\oplus^{1 *}$
}
${ }^{1}$ Faculty of Medicine, Universidad Autónoma del Estado de México, Toluca, Estado de México, México
${ }^{2}$ Department of Biological Systems, Universidad Autónoma Metropolitana, Ciudad de México, México

(Received July 15, 2021; Revised September 24, 2021; Accepted September 28, 2021)

\begin{abstract}
The actinobacteria, also referred to as actinomycetes, have been the most widely used bacteria to produce industrial interest compounds due to their great biosynthetic capacity to generate structural diversity molecules. The actinobacteria with the most significant biosynthetic potential are the genus Streptomyces, Saccharopolyspora, and Micromonospora containing groups of biosynthetic genes such as polyketide synthase systems, non-ribosomal peptide synthase systems, terpenoid systems, ribosomally synthesized and posttranslationally modified peptide systems, among others. This review focuses on genomic mining techniques and current helpful software to search for new natural products in actinobacteria. Currently, molecular techniques have been developed to improve the isolation of natural products, and bioinformatics programs, many are free to access, have been designed to analyze genes and microbial genomes that predict new molecule production. Thanks to these techniques, new natural products of industrial interest have been found in rare actinobacteria such as Nocardia and Rhodococcus.
\end{abstract}

Keywords: Actinobacteria; bioinformatics; genomic mining. () 2021 ACG Publications. All rights reserved.

\section{Introduction}

In the 1980s, there were significant advances in genetics and phylogenetic analysis, such as sequencing the rrs gene, which codes for ribosomal RNA, used to identify bacterial species; this led to the discovery of new species and the taxonomic reassignment of others already known. In the 1990s, the improved PCR and DNA sequencing techniques had a rapid expansion, leading to the sequencing of complete bacterial genomes, promoting research, and discovering new natural products [1]. In 2000, biosynthetic gene clusters (BGC) were searched for in the genome of microorganisms, mainly in actinobacteria, to predict secondary metabolites' production with pharmacological activity. The study of genomic sequences made it clear that actinobacteria have greater biosynthetic capacity than previously known; however, it was also discovered that there are cryptic gene clusters even in widely studied species biosynthetic pathways [2].

The best studied BGCs are the polyketide synthase systems (PKS) and non-ribosomal peptide synthase systems (NRPS) that are distributed in the genomes of actinobacteria; however, despite the

* Corresponding author: E-Mail ninfard@ hotmail.com

The article was published by ACG Publications

http://www.acgpubs.org/journal/records-of-natural-products July-August 2022 EISSN:1307-6167

DOI: http://doi.org/10.25135/rnp.286.2107-2132

Available online: October 14, 2021 
wealth of information that exists, there is still much to be discovered for the development of new natural products as therapeutic alternatives.

\section{Actinobacteria}

Actinobacteria are a vast family of Gram-positive microorganisms with high GC content in their genome and great biosynthetic capacity. They are the best producers of metabolites with applications in medicine, agriculture, and industry; their secondary metabolism is so vast that they are responsible for producing two-thirds of all naturally occurring antibiotics currently used clinically and many more compounds such as anticancer, anthelmintics, and antifungals [3].

These bacteria inhabit diverse environments such as acidic soils [4], saline waters [5], desert soil [6], freshwater [7], Antarctic [8], and other ecosystems, including extreme ones [9]; some species are symbionts of insects, plants, and marine animals [10]. There are pathogenic species of actinobacteria that infect higher organisms [11]. The primary infection caused by these etiologic agents is called actinomycetoma and occurs most frequently in immunodeficient individuals [12].

In 1940, Waksman and Woodruff discovered the first antibiotic produced by an actinobacterium, actinomycin. From that moment started the "actinomycete era," where several actinobacteria species were isolated and identified, demonstrating that they are significant producers of natural pharmacological compounds [13]. The genome sequence of Streptomyces coelicolor A3 [14] revealed that it contains genes encoding for 20 BGCs, but many of these are not expressed under normal laboratory culture conditions.

The most prominent genera as secondary metabolite producers are Streptomyces, capable of synthesizing the antibiotic actinomycin [15] and the antifungal candicidin used extensively in the clinic [16]; Micromonospora, producer of the antibiotics anthracycline and gentamicin [17] and Saccharopolyspora responsible for the biosynthesis of erythromycin [18]. Actinobacteria other than the genus Streptomyces are termed "rare" and are significant sources of natural products.

Currently, it is necessary to increase the search for bioactive molecules in actinobacteria to develop certain countermeasures in context of the emerging threat of multidrug-resistant pathogens. This family of bacteria is promising in the face of this challenge. Table 1 shows some natural products synthesized by "rare" and little studied actinobacteria to search for secondary metabolites.

Table 1. Natural products synthesized by "rare" actinobacteria and the type of BGC responsible.

\begin{tabular}{|c|c|c|c|c|}
\hline Compound & Activity & $\begin{array}{l}\text { Type of BGC } \\
\text { present }\end{array}$ & Actinobacteria & Reference \\
\hline Nocardicin A & Antibiotic & NRPS & N. uniformis & [19] \\
\hline Brasilicardin & $\begin{array}{l}\text { Immunosuppressant } \\
\text { and cytotoxicant }\end{array}$ & Terpenoid & N. brasiliensis & [20] \\
\hline Nocobactin NA & Cytotoxic & $\begin{array}{l}\text { Hybrid } \\
\text { NRPS/PKS }\end{array}$ & N. farcinica & [21] \\
\hline Amamistatin A & Antitumor & & $N$. asteroides & [22] \\
\hline Nocarditiocin & $\begin{array}{l}\text { Antibiotic, antiviral } \\
\text { and anticancer }\end{array}$ & RiPP & N. pseudobrasiliensis & [23] \\
\hline 2'-Chloropentostatin & Antibiotic & $\begin{array}{l}\text { Adenosine } \\
\text { deaminase }\end{array}$ & Actinomadura sp. & [24] \\
\hline 2'-amino dA & Antibiotic & $\begin{array}{l}\text { Adenosine } \\
\text { deaminase }\end{array}$ & Actinomadura sp. & [24] \\
\hline Nomicin & Antitumor & PKS-I & Actinomadura sp. & [25] \\
\hline $\begin{array}{l}\text { Polychlorinated } \\
\text { biphenyls }\end{array}$ & Degradative enzymes & Putative genes & Rhodococcus sp. & [26] \\
\hline
\end{tabular}




\section{Biosynthetic Systems Involved in the Production of Secondary Metabolites}

Bacteria produce secondary metabolites to communicate and compete in their environment. These can be used for the development of new natural products of pharmacological interest. Natural products are synthesized by biosynthetic gene clusters (BGCs) such as polyketides, non-ribosomal peptides, saccharides, alkaloids, and terpenoids. These are built by modules that catalyze specialized enzymes' production, regulatory, transporter, and processing proteins. They ultimately create diverse chemical structures that can be used as antibiotics, anticancer drugs, immunosuppressants, cholesterol reducers, food additives, plant protection agents, and more [27].

Systems produce most bioactive molecules called polyketide synthases (PKS) and nonribosomal peptide synthase systems (NRPS). Bacterial PKSs and NRPSs can be classified into three types, depending on the configuration of their modules: PKS-I, PKS-II, and PKS-III; NRPS-I, NRPSII, and NRPS-III, respectively. The PKS and NRPS systems encode enzymes with very similar functions that allow the construction of structures derived from the hybridization of both. The proportion and assembly are variable factors, and there may be more PKS systems in a BGC than NRPS or vice versa; this implies a wide variability in the synthesized products $[28,29]$.

\subsection{Polyketide Synthase Systems (PKS)}

PKS-I systems are multienzyme complexes closely related to fatty acid synthases (FAS), synthesizing molecules from the substrate acyl-CoA to form polyketides with variable structures due to domains with the enzymatic activity of mainly ketosynthase (KS), acyltransferase (AT), and an acyl carrier protein (ACP). Occasionally it has auxiliary domains such as thioesterase (TE), keto-reductase (KR), dehydratase (DH), and others for the configuration of the formed structure [30] (Figure 1).

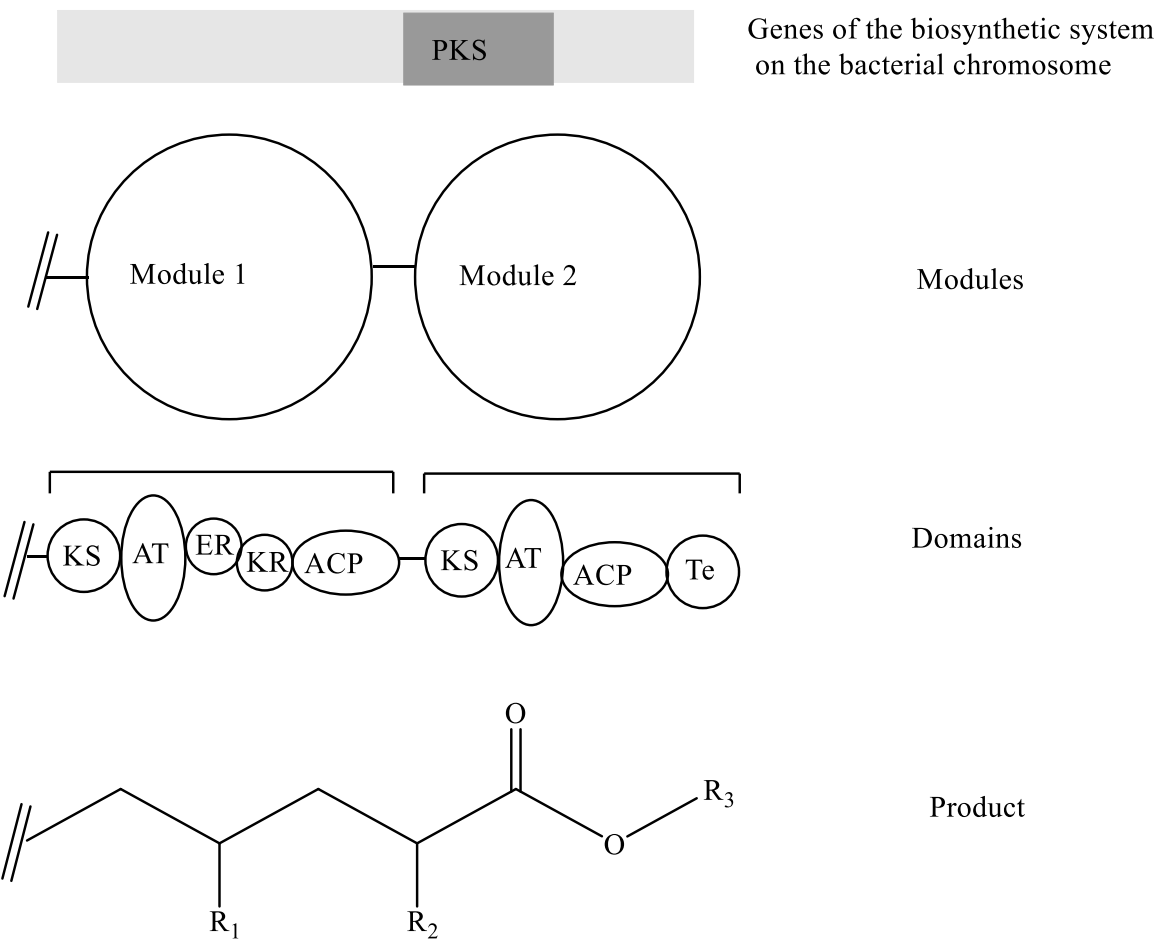

Figure 1. Conformation of a PKS system 


\subsection{Non-Ribosomal Peptide Synthetase Systems (NRPS)}

NRPS systems are an enzyme complex, like PKS; the order of the modules reflects the nonribosomal peptide product synthesized. The modules consist of three essential domains, adenylation (A), condensation (C), and a peptidyl carrier protein (PCP). It may also have auxiliary domains such as cyclization $(\mathrm{Cy})$ and epimerization (E) that give diversity to the final product [30] (Figure 2).

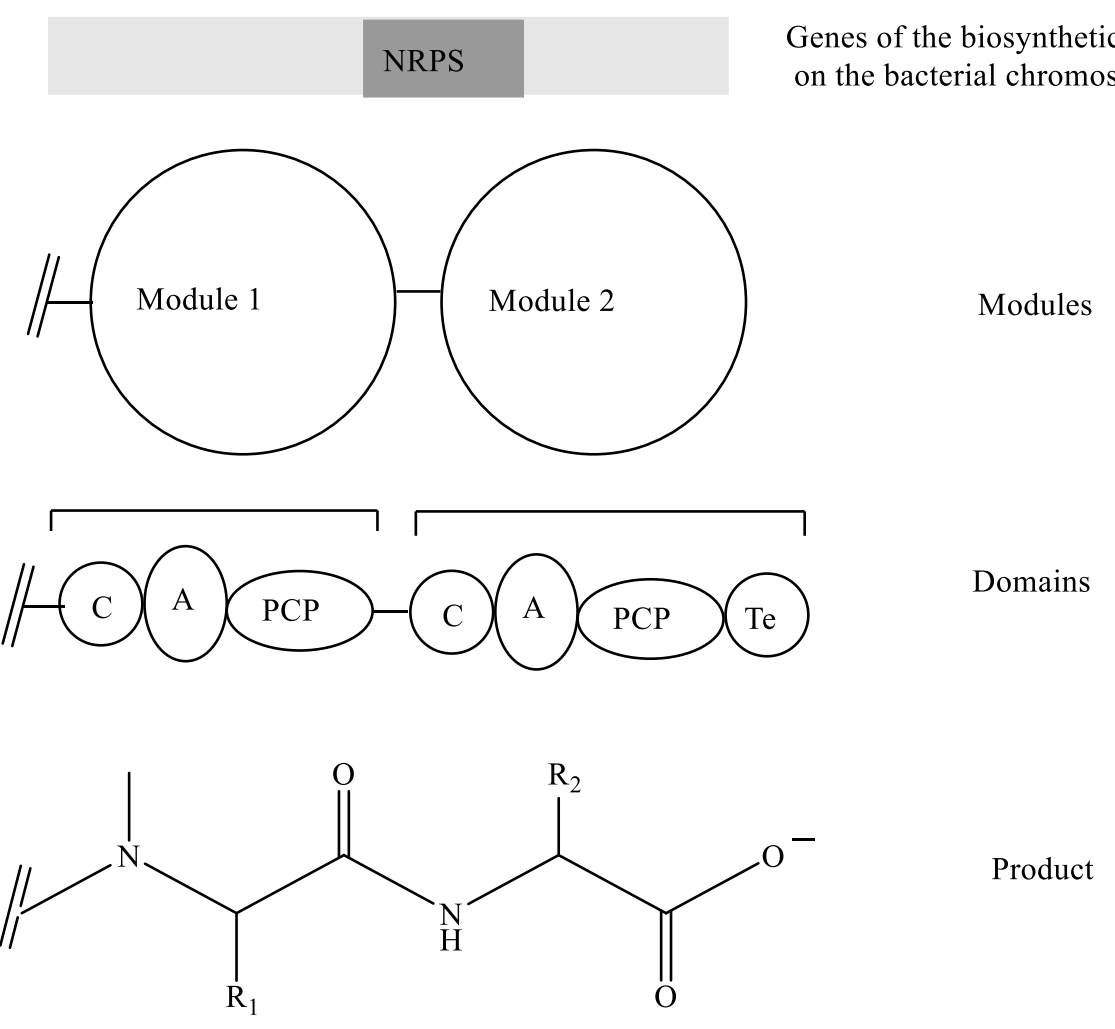

Figure 2. Conformation of a NRPS system

\subsection{Terpene Synthase Systems (TS)}

Terpene synthase (TS) systems produce secondary metabolites with more than 80,000 described compounds. All terpenoids are synthesized from C5 isoprenoid precursors, isoprenoid diphosphate (IPP), and dimethylallyl diphosphate (DMAPP) that are linked by isoprenyl transferases to form substrates of different lengths (Figure 3). TSs are divided into type I by abstraction of diphosphate and type II by protonation of an olefinic double bond [31]. Due to their structural diversity, they have a wide range of industrial applications [32]. 


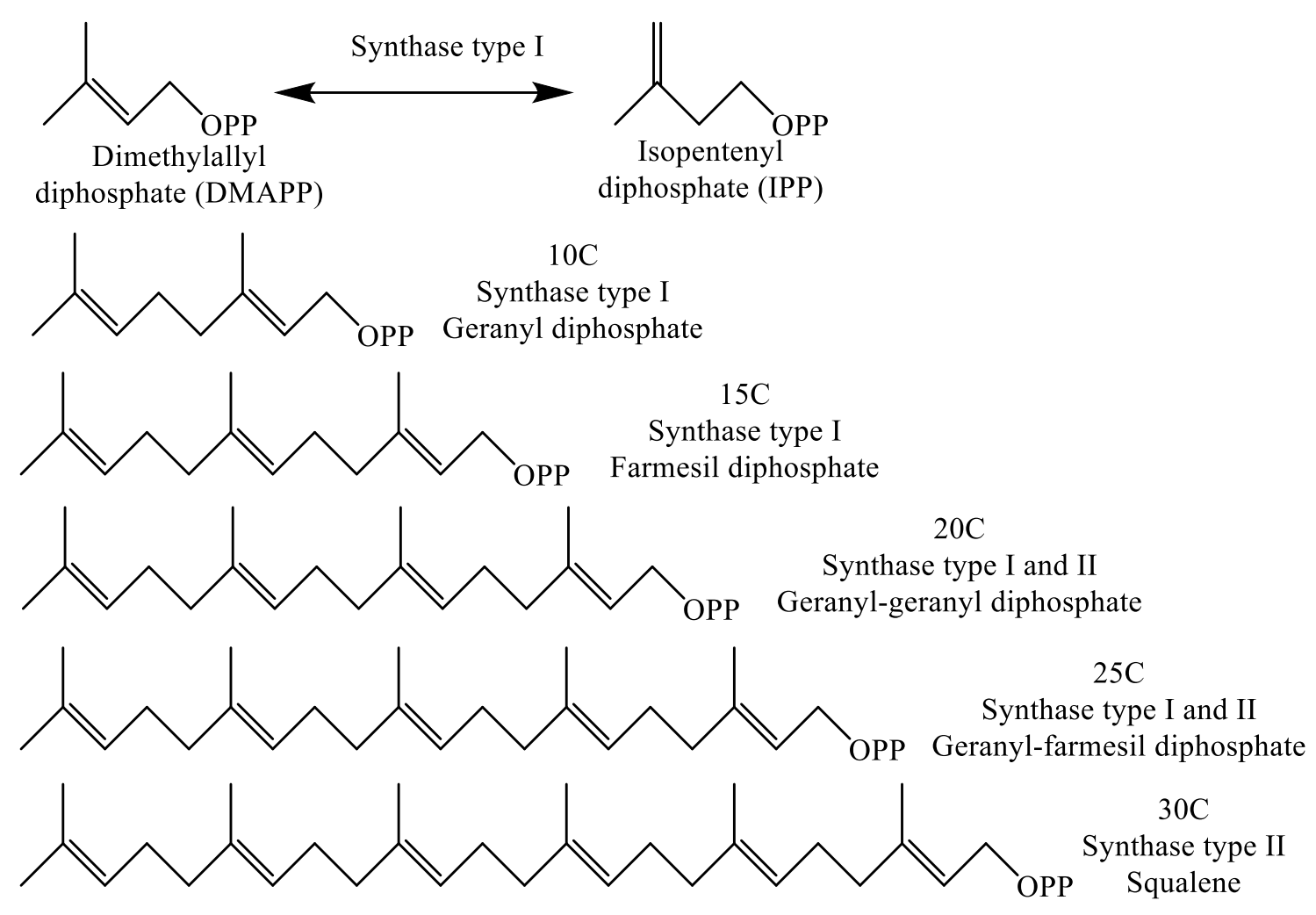

Figure 3. 5C terpenoid precursors and structures derived from the union of two or more precursor molecules will form the skeletons for complex terpenoid molecules.

\subsection{Ribosomally Synthesized and Post-translationally Modified Peptide Systems (RiPP)}

RiPPs is a type of natural compound-producing systems with complex chemical structures. They are produced from a short precursor peptide (PP) synthesized by the ribosome composed of a leader peptide and a core peptide post-translationally modified by RiPP tailoring enzymes (RTE) that generate various structural features of peptides. The core peptide is cleaved from the leader peptide once modifications have been made to give a final product with activity (Figure 4). Unlike PKS and NRPS systems that are made up of multimodular complexes, the biosynthetic logic of RiPP means that there are few conserved features in peptides of this type [33].

These biosynthetic systems have accessory genes related to the biosynthesis of natural products divided according to their function into precursor synthesis genes, regulatory genes, resistance genes, genes for processing specific modifications tailoring [34, 35].

Secondary metabolite prediction is achieved by analyzing BGCs using metabolomic data, chemical structure predictions, mutant libraries, and heterologous expression. These analyses are performed on bioinformatics platforms that have continuously been updated and are more userfriendly. They are currently used for bacterial, fungal, and plant genomic analysis, mainly [36].

Several studies have argued that the discovery of new natural products has been sustained; however, the number of approved and regulated compounds is very few, probably because most are not produced in significant quantities, or BGCs are cryptic, and the producing strains are not genetically tractable. This challenge is overcome by using genomic mining strategies that have now advanced and have enabled the discovery and production of more significant new natural products [37]. 

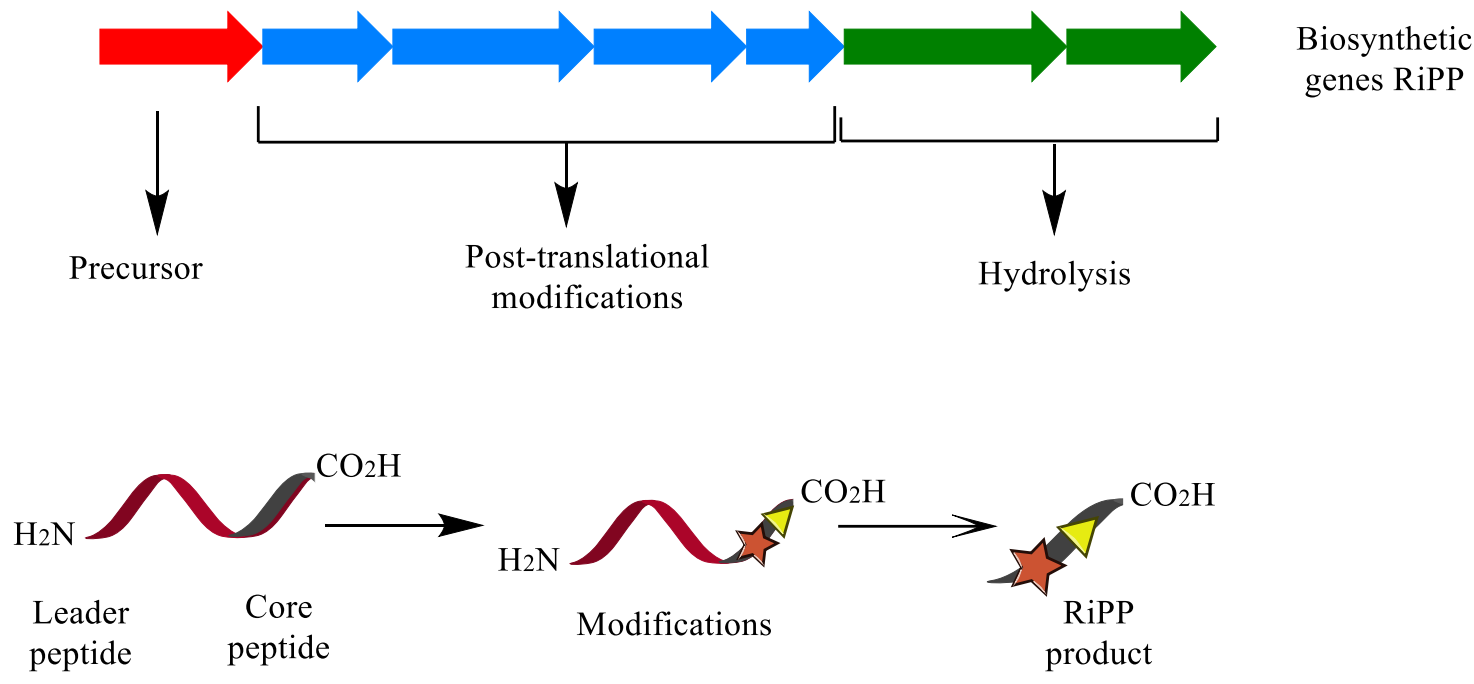

Figure 4. Diagram of RiPP peptides' biosynthesis, the modifications are different and complex, resulting in products with molecular diversity

\section{Bioinformatics Tools for Biosynthetic Systems Search}

Since the first bacterial genomes were sequenced, interest in discovering new natural products has increased, leading many researchers to develop molecular biology techniques and bioinformatics tools for BGC prediction. Identifying and exploiting a large amount of genomic data is growing every day.

Bioinformatics tools compare thousands of genes and entire genomes to predict molecular structures. For years, computer programs and algorithms have been designed to detect BGC in nucleotide sequences. These tools have improved the quality of genomic analysis in a short time.

Bioinformatics tools generally use selected cuts to identify genes or domains precisely in a group of aligned sequences to detect known classes of biosynthetic pathways. Some BGCs are rapidly detected, such as the PKS and NRPS systems. Many biosynthetic pathways are known, and prediction reliability is high in bioinformatics programs such as the Antibiotics and Secondary Metabolite Analysis Shell (antiSMASH) [38]. These systems encode enzymes from the same families, such as oxidoreductases, methyltransferases, CoA-ligases, and cytochrome P-450. They also encode operons similar to the families of known transcriptional regulators [39].

On the other hand, it is computationally challenging to detect novel BGCs. Some BGCs, such as RiPP, have distinctive shared and tiny genes that cannot be detected by the algorithms. Table 2 describes some bioinformatics programs used in gene and genome analysis to search for metabolites that are freely available.

Computational advances have changed how natural compounds are discovered and make substantial amounts of genomic information available to every researcher. Bioinformatics helps to understand the role of natural products in microbial ecology and the microorganism-host relationship. The challenges that can currently be solved with the help of bioinformatics are [52]:

- Develop computational programs of the ecological distribution of BGC clusters that reveal a subset that has evolved to produce a molecule targeting eukaryotic enzymes.

- $\quad$ Refine the search process to predict gene clusters whose small molecule products have a target expressed in another organism. 
Table 2. Software used for BGC search and analysis

\begin{tabular}{|c|c|c|}
\hline Database & Characteristics & References \\
\hline AntiSMASH & $\begin{array}{l}\text { Identification, annotation, and analysis of secondary metabolite } \\
\text { biosynthesis genes in bacterial and fungal genomes. }\end{array}$ & [38] \\
\hline NP.searcher & $\begin{array}{l}\text { Sequence scanning of prokaryotic genomes for polyketides, non- } \\
\text { ribosomal peptides, and mixed-combination natural products. }\end{array}$ & [40] \\
\hline ClustScan & $\begin{array}{l}\text { Search for PKS, NRPS, and hybrid PKS/NRPS biosynthetic } \\
\text { enzymes; shows predicted chemical structures from prokaryotic, } \\
\text { invertebrate animal, and metagenomic DNA. }\end{array}$ & [41] \\
\hline MultiGeneBlast & $\begin{array}{l}\text { Homology search with operons or groups of genes as basic units } \\
\text { rather than individual genes. }\end{array}$ & [42] \\
\hline MIBiG & Database of biosynthetic genes and their natural products. & [43] \\
\hline DoBISCUIT & $\begin{array}{l}\text { Integration of current bibliographic information; provides } \\
\text { standardized descriptions of genes, modules, and domains related } \\
\text { to gene clusters. }\end{array}$ & [44] \\
\hline ClusterMine360 & Prokaryotic PKS and NRPS gene cluster database. & [45] \\
\hline ChEBI & $\begin{array}{l}\text { Search for information focused on immunology and natural } \\
\text { products. It is a dictionary of molecular entities, small chemical } \\
\text { compounds, natural or synthetic products used in organisms' } \\
\text { processes. }\end{array}$ & [46] \\
\hline ChEMBL & $\begin{array}{l}\text { Pooling chemical, genomic and bioactivity data to translate } \\
\text { genomic information into effective new drugs. }\end{array}$ & [47] \\
\hline KNApSAcK & $\begin{array}{l}\text { Focused on research in metabolomics, nutrigenomics, and food } \\
\text { omics, it can also develop new drugs and materials. }\end{array}$ & [48] \\
\hline NRPSpredictor & Prediction of bacterial and fungal NRPS A domains. & [49] \\
\hline NORINE & Entirely dedicated to NRPS analysis. & [50] \\
\hline StreptomeDB & $\begin{array}{l}\text { Search for information on molecular structures produced by } \\
\text { Streptomyces. }\end{array}$ & [51] \\
\hline
\end{tabular}

These strategies are intended to mimic existing relationships between some organisms; for example: the symbiosis between Streptomyces and some sea sponges, where the bacteria produce secondary metabolites to protect the sponges against infections caused by other microorganisms; this relationship also occurs with Streptomyces and wasps [53].

Approaches based on molecular studies at the genomic, metagenomic, transcriptomic, proteomic, and metabolomic levels are essential for discovering new bacterial resources and exploiting key molecular processes associated with the production and action of secondary metabolites; "omics" approaches in conjunction with bioinformatics resources for molecular analysis and modeling are driving biotechnological advances.

\section{Current Techniques in the Search for New Natural Products in Actinobacteria}

A traditional and low-cost approach is to induce expression of cryptic biosynthetic genes by media supplementation; for example, the lanthanides scandium and lanthanum were found to induce silent gene expression in Streptomyces spp. by finding novel compounds. Since rare elements may be distributed worldwide, microorganisms such as Streptomyces may acquire the ability to respond to low levels of these elements throughout their evolutionary history, possibly adapting their physiology to demanding environmental conditions [54].

Another technique currently employed is co-culture to induce metabolic pathways of secondary metabolites. The goal is to send a missing regulatory signal by using two or more specific bacterial strains known to interact; for example, the interaction of Tsukamurella pulmonis, Rhodococcus erythropolis, and Corynebacterium glutamicum increase metabolite biosynthesis by up to $85 \%$ in Streptomyces strains [55].

Moreover, the search for new compounds led to genomic engineering's idea to predict, produce, and isolate natural products. Even the most studied and exploited strains are known to 
contain more significant biosynthetic potential than previously thought. Large amounts of genomic data can be analyzed with the thousands of bacterial genomes available in addition to new molecular and bioinformatics technologies. Current genomic mining techniques are based on two strategies for gene modification and modulation of the regulated system: changes in the native host and an engineered heterologous host. The methods for gene modification and modulation most used are classical gene mining, comparative genome mining, phylogeny-based mining, mining based on resistance genes, mining of regulators and metagenomics.

\subsection{Classical Gene Mining}

It is based on the search for conserved genes responsible for the encoding of enzymes involved in the synthesis of secondary metabolites. These genes are well studied and found in many microorganisms, such as NRPS, PKS, RiPP, aminoglycosides, and terpenoids. The genes found are not always expressed; some are cryptic or silent genes. An example of this technique is shown in Figure 5 with kinamycin-producing Streptomyces ambofaciens and its derivatives [56].
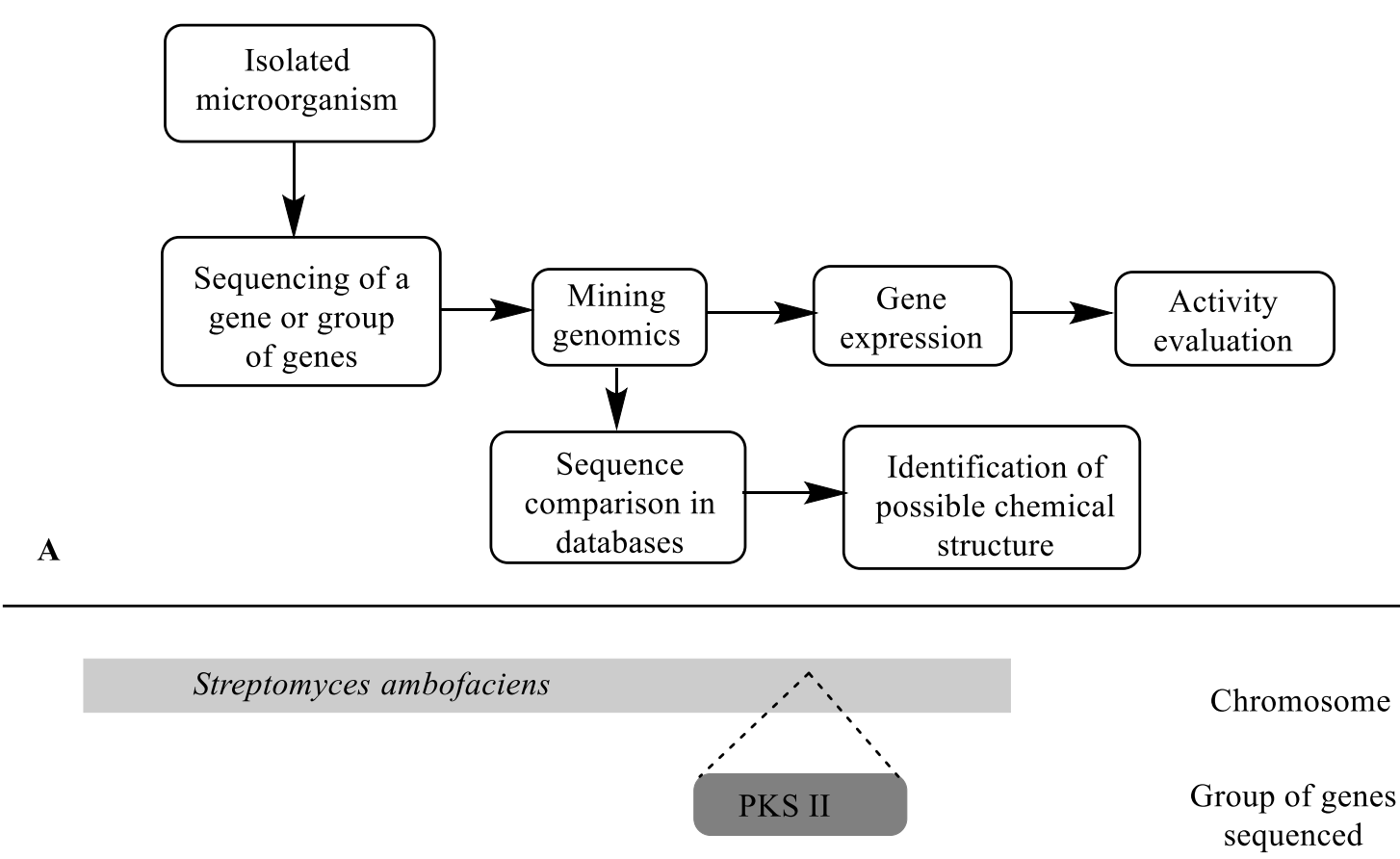

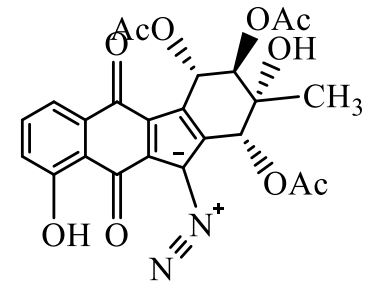

Kinamycin C

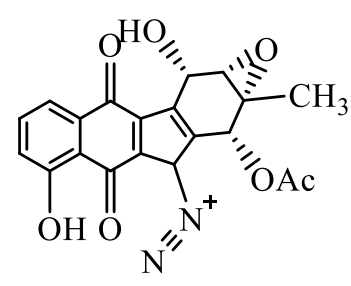

Epoxy-kinamycin

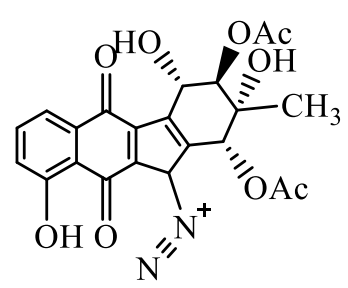

Kinamycin D

B

Figure 5. A) Diagram of classical mining development for the search of new natural products.

B) Biosynthetic genes are searched using specific primers in a PCR reaction, the amplified genes are sequenced for bioinformatic analysis and prediction of chemical structures

\subsection{Comparative Genome Mining}

It employs software such as antiSMASH to compare BGCs in whole genomes of many microorganisms. All genes involved in secondary metabolite production are identified, and cryptic or 
silent genes can be found. Comparative genome mining is becoming a routine analysis technique for newly assembled genomes. Generally, this technique is employed in conjunction with gene activation and regulation techniques. The technique is illustrated in Figure 6 with congocidin produced by Streptomyces ambofaciens [57].
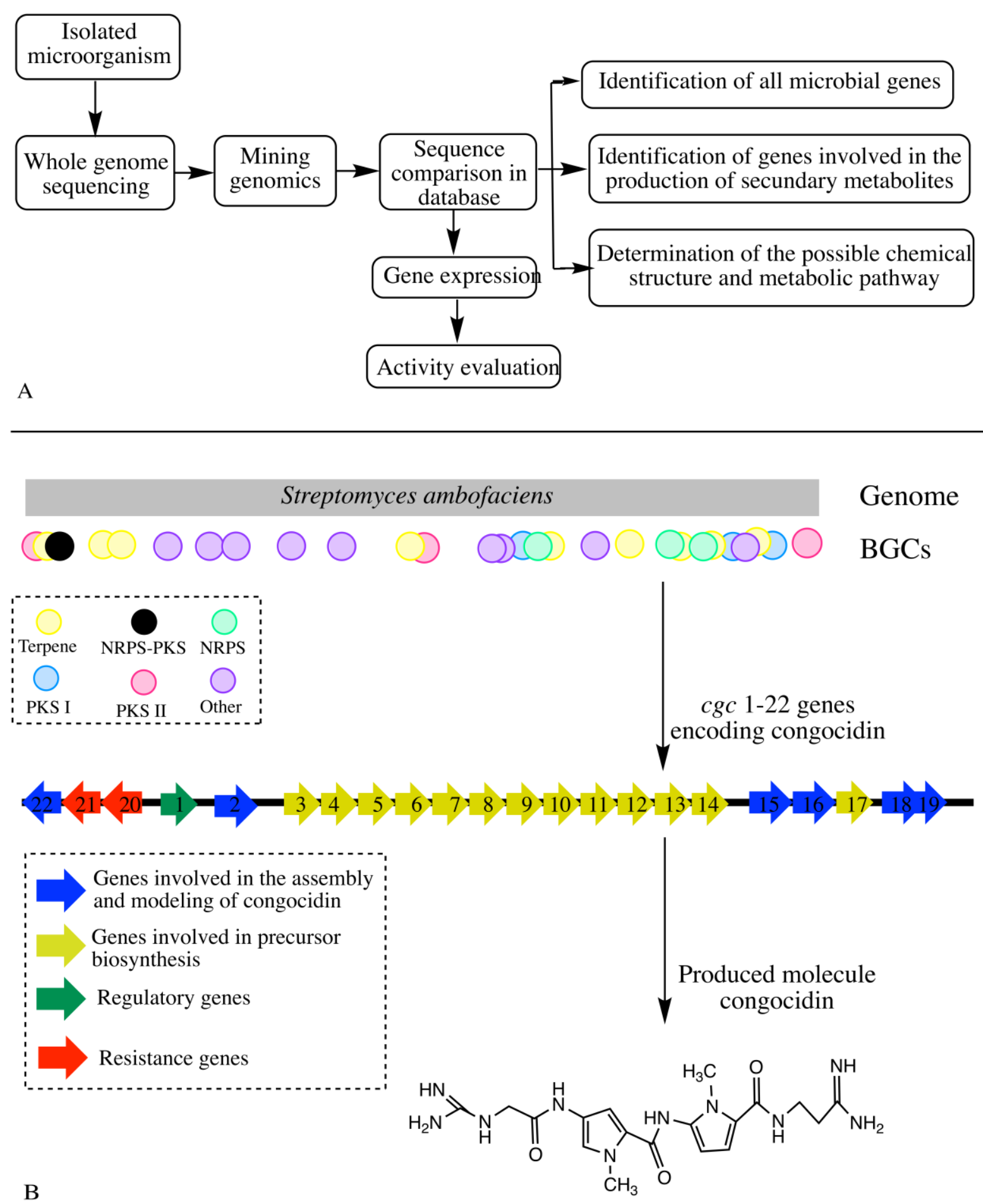

Figure 6. A) Procedure to search for BGCs in bacterial genomes. B) The genome is analyzed with bioinformatics programs to know all the BGCs, the genes of interest are chosen to produce one or more natural products 


\subsection{Phylogeny-Based Mining}

It uses phylogenetic methods to find secondary metabolite genes based on the idea that there is an evolving defense system that allows the production of new molecules by exchanging domains and modules in bacteria as a cause of the development of an adaptive immune system. Conserved genes are searched for, and the production of new molecules is mapped so that compound-producing lineages can be traced. A phylogenetic cluster may be able to produce similar compounds. Nocobactin produced by several genus Nocardia species was studied using phylogeny-based mining [21, 58], as shown in Figure 7.
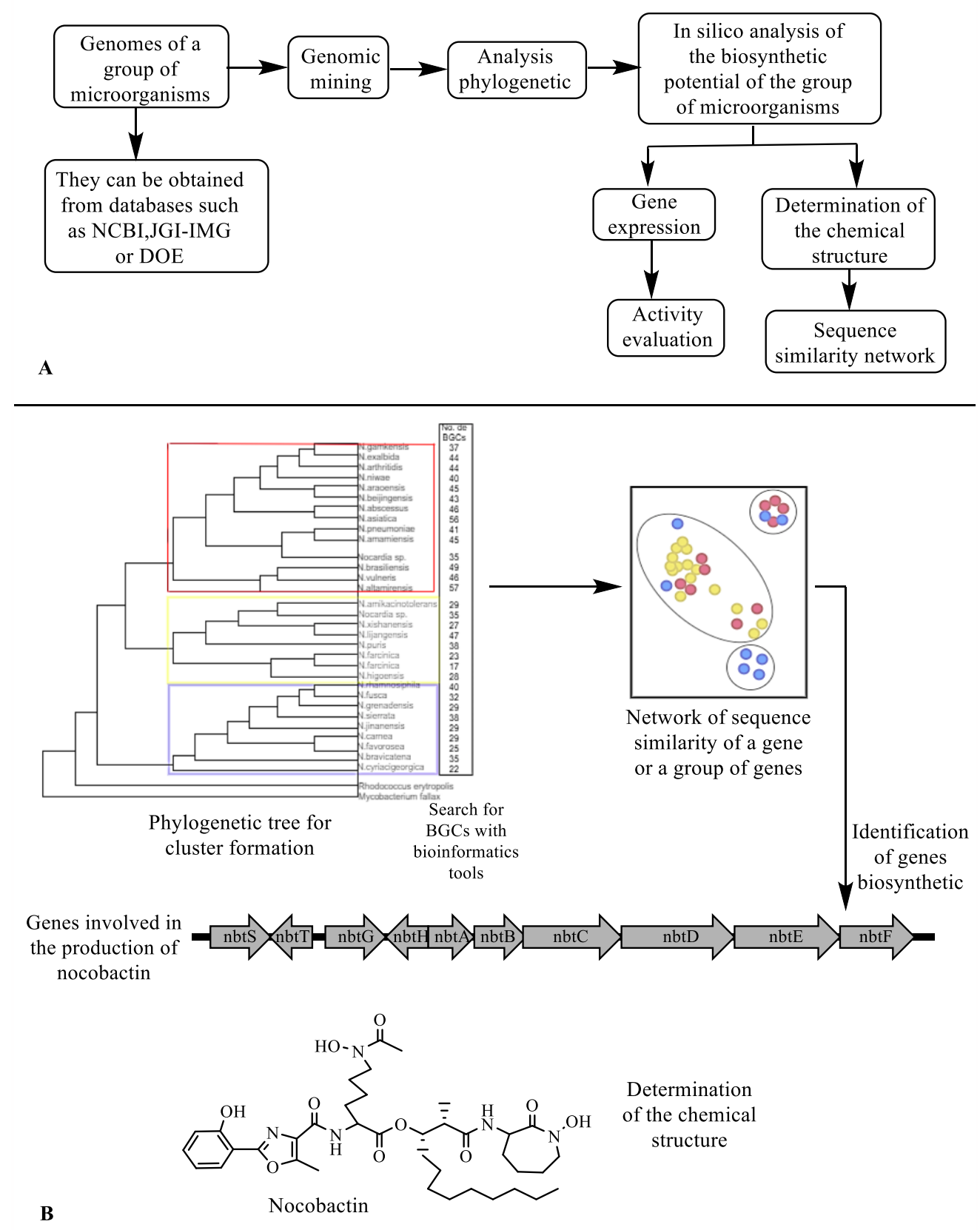

Figure 7. A) Procedure for the search of new natural products from phylogenetic techniques. B) Phylogenetic relationships are searched in genomes or groups of BGCs in a group of microorganisms (species or genera); a network analysis of the clusters formed allows finding related groups. The BGCs are compared to predict chemical structures synthesized by the same group of microorganisms 


\subsection{Mining Based on Resistance Genes}

Its function is to detect BGCs through the self-resistance mechanisms of an antibioticproducing bacterium or another compound. It is based on encoding the set of biosynthetic genes, regulatory elements, transporter proteins and resistance mechanisms. The gene set can be from $10 \mathrm{~kb}$ to as large as $150 \mathrm{~kb}$, making the cut-and-paste technique challenging. Cosmid libraries are first assembled, and host genes that function as promoters are assembled. At this point, there may be an absence of promoter recognition and ribosome binding sites by the host leading to low or no expression of biosynthetic enzymes; this obstacle is overcome by replacing the regulatory elements with genes suspected to function well within the host. This technique is used to express cryptic or silent genes; an example is shown in Figure 8 using Salinispora pacifica genes and using Streptomyces as a recipient [59].
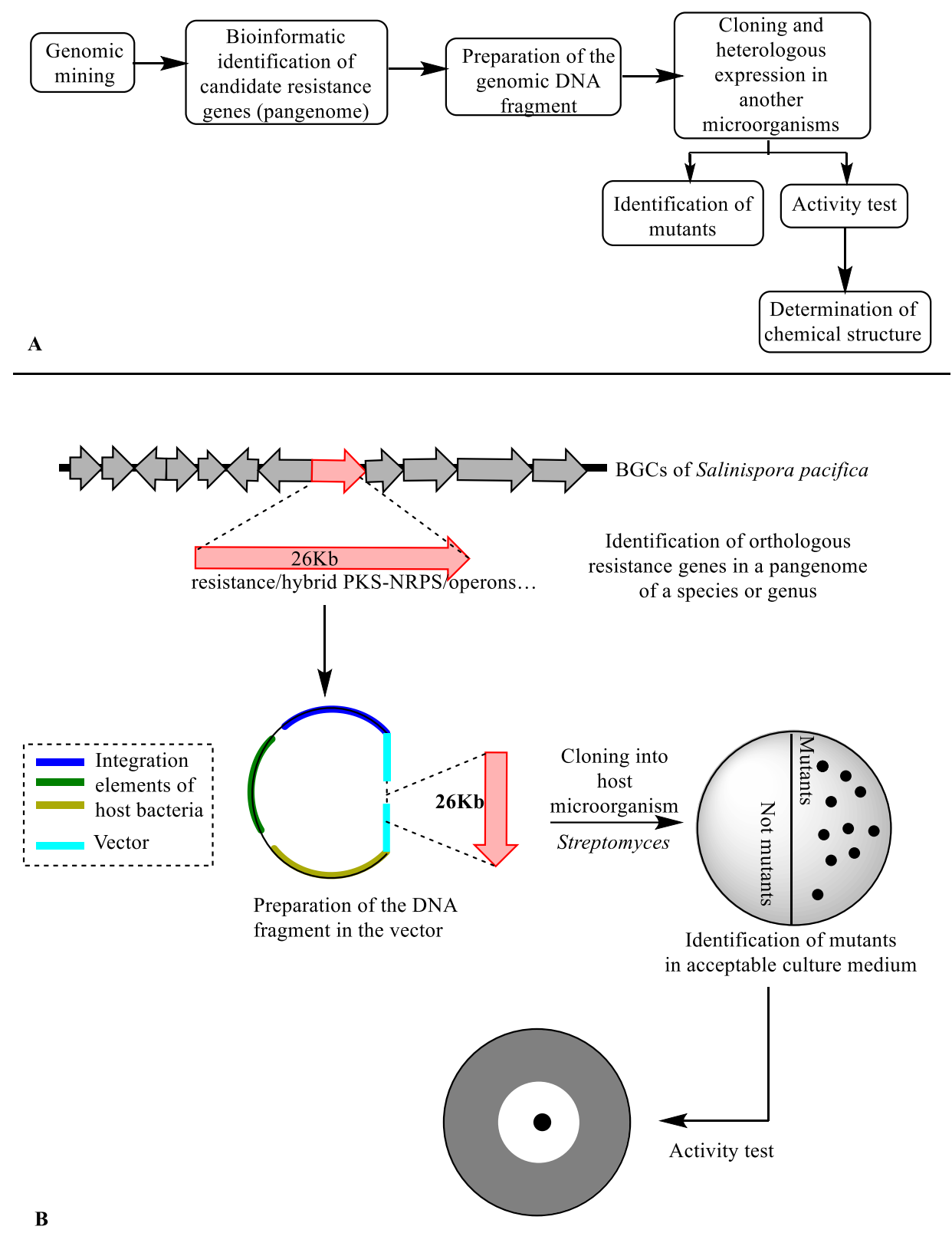

Figure 8. A) Procedure to find new natural compounds by regulation of resistance genes. B) BGCs, and other genes involved in biosynthesis are searched, the set of genes is attached to a vector, heterologous expression can be performed, and other regulatory genes can be 
integrated, the vector and the set of genes are inserted into the final host. The mutant is grown and reproduced to express the biosynthetic genes

\subsection{Mining of Regulators}

It seeks to activate the production of cryptic or silent BGCs by regulating repressor or activator genes to produce natural compounds [60]. Streptomyces ambofaciens genes were activated to produce stambomycin using this technique [61] (Figure 9).
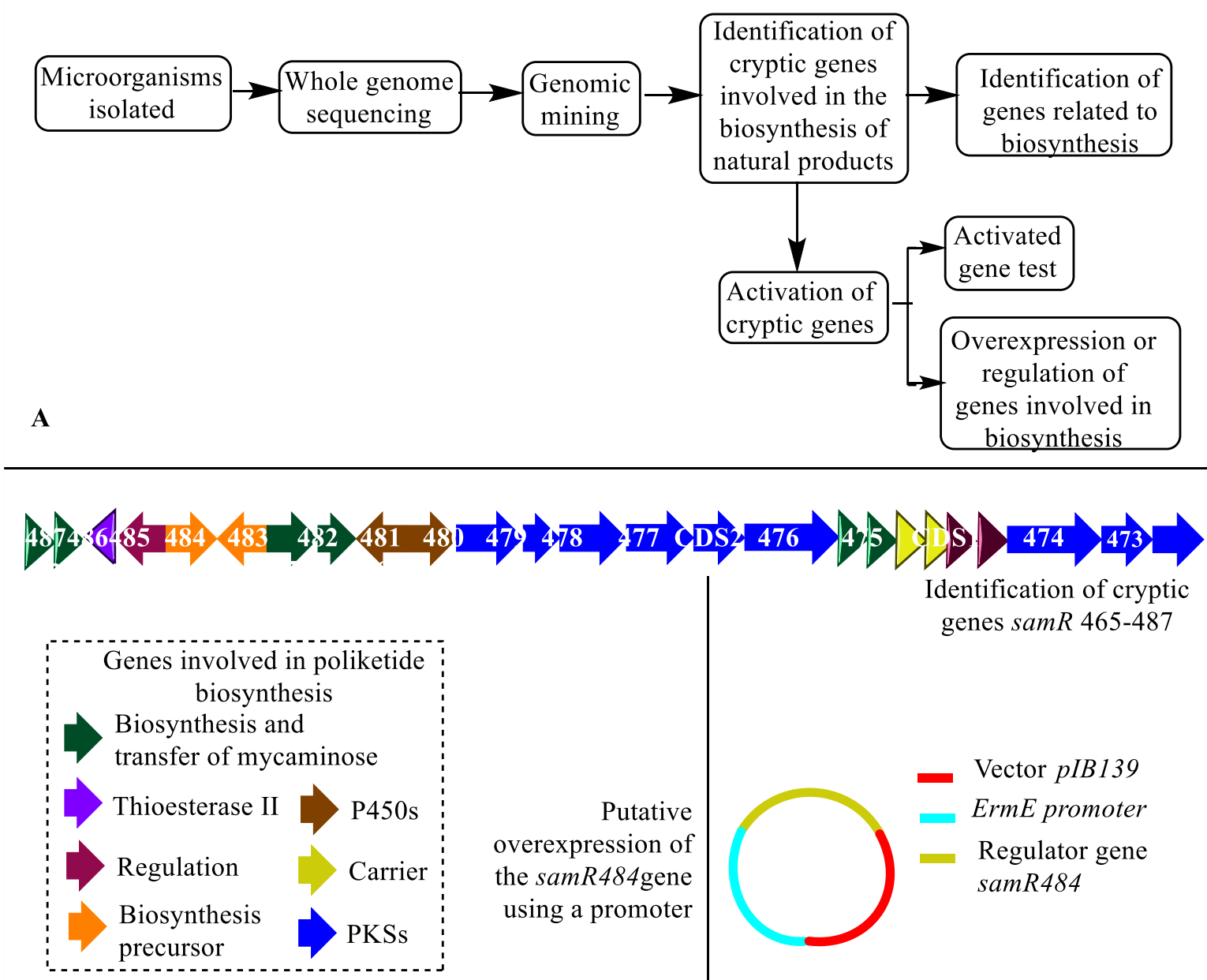

Identification of cryptic genes $\operatorname{samR} 465-487$

B

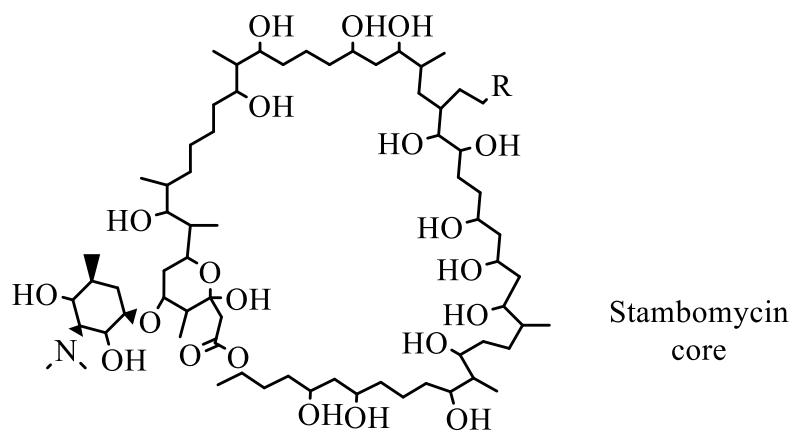

Figure 9. A) Procedure to find new natural compounds by gene regulation. B) BGC and regulatory genes involved in biosynthesis are searched, the gene set is attached to a vector that will have a promoter inserted into the native microorganism to express the biosynthetic genes 
Natural products in Actinobacteria

\subsection{Metagenomics}

It allows obtaining bioactive molecules through direct cloning of bacterial DNA from any environmental source without growing the bacteria in the laboratory, which is often impossible. Approaches can be of two types: sequence-based metagenomics, based on sequencing and bioinformatics analysis of a sample to identify BGCs of interest; and function-based metagenomics, based on direct functional screening of clones with discrete activities to identify clones of interest. The disadvantage of metagenomics is the complexity of assembling genomes that may contain up to 105 different species, as in a typical soil sample [1]. Techniques to find BGCs can be those mentioned above.

Most Nocardia species can produce a wide range of natural compounds despite being less studied. Their genome sequencing shows that they have cryptic BGCs to synthesize versatile compounds if these silent genes can be promoted to be expressed. Recent research has succeeded in producing novel compounds from Nocardia that can be used as alternative therapies [62,63].

Mishra et al. (2019) [62] elucidated the genes and biosynthetic mechanism of a novel compound using genomic mining, metabolite profiling, and bioinformatics of Nocardia sp. strain CS682. By inactivating nargenicin A1-producing genes, PKS-I genes activated another metabolic pathway of the PKS-III system that encoded a 1,3,6,8-tetrahydroxynaphthalene (THN) derivative called IBR-3; the biosynthetic genes of the new THN (orf1, orf2, thnM1, thnT1, thnG, thnA, thnM2, thnM3, thnT2, and orf3), their possible catalytic functions and the biosynthetic pathway hypothesis were predicted. The compound IBR-3 showed protective activity against UV radiation, a molecule with cosmetic potential as an anti-photoaging and photoprotective product.

In another study, Awakawa et al. (2018) [63] reprogrammed the structure in the domains forming an NRPS/PKS hybrid encoding antimycin by recreating an antimycin derivative in a Streptomyces lividans strain. They established heterologous expression systems of the cyclic peptides of the antimycin (JBIR-06 and neoantimycin) and redesigned their biosynthesis using bioinformatics tools and evolutionary analysis. They first achieved the neoantimycin ring's contraction, subsequently expanded the JBIR-06 ring, and finally diversified the JBIR-06 alkyl chain by incorporating alkylmalonyl-CoA extension units, thus creating unnatural derivatives of the antimycin with high yields. This study represents a strategy for domain and module diversification.

There are advances in studies with "rare" actinobacteria; however, obstacles remain. DNA assembly and cloning techniques in actinobacteria are complex due to their high G+C content, repetitive and highly conserved sequences in PKS and NRPS genes, and the length of BGCs often spanning more than $100 \mathrm{~kb}$. Therefore, friendlier cloning tools are required to work with these bacteria [64]. Some strategies for assembly and cloning of DNA regions in actinobacteria are as follows:

iCatch (iBrick and Cas9-Assisted Targeting of CHromosome). It is a tool to "capture" large regions of DNA. It is based on creating DNA segments flanked by Xbal and Spel restriction sites to generate compatible cohesive ends after digestion with restriction enzymes, allowing easy assembly [65].

DiPaC (Direct Pathway Cloning). It is used for cloning short to medium-sized BGCs with high GC content. Long amplicon PCR and introduction of homologous nucleotide bumps is performed, allowing DNA assembly, BGC refactoring, and direct transfer to any in vitro vector suitable for heterologous expression [66].

CRISPR/Cas9 (Clustered Regularly Interspaced Short Palindromic Repeats-Cas9 endonuclease). It is an editing tool that works through an RNA-guided nuclease that can be programmed to target any sequence by providing a short synthetic RNA sequence (20-50 nucleotides). It is widely used due to its ease of use and high specificity. It is continuously employed in genomic mining techniques. In actinobacteria, it is practical; however, it has been shown to be toxic [67].

Modified Gibson assembly. It is a method for cloning large DNA fragments with high GC content. It allows seamless assembly of multiple fragments (up to $900 \mathrm{~kb}$ ), requiring overlapping sequences of neighboring DNA molecules. The high GC content can generate the vector to self-ligate, so single-stranded cohesive ends with high AT content are added, reducing up to $45 \%$ self-ligation [68]. 
Researchers have used genomic engineering approaches to activate silent genes to discover new natural compounds or produce with high yields of already known compounds; some are briefly described in Table 3.

Table 3. New natural compounds discovered using current search techniques in actinobacteria

\begin{tabular}{|c|c|c|c|}
\hline Compound & Producing bacteria & Description & References \\
\hline IBR-3 THN derivative & Nocardia sp. & $\begin{array}{l}\text { By inactivating the nargenicin } \\
\text { A-producing genes, they } \\
\text { activated another cryptic } \\
\text { biosynthetic pathway that } \\
\text { encoded a novel compound. }\end{array}$ & [62] \\
\hline Antimycin derivatives & Streptomyces lividans & $\begin{array}{l}\text { Reprogramming of the } \\
\text { NRPS/PKS hybrid system's } \\
\text { domains and modules to obtain } \\
\text { higher yields in the production } \\
\text { of antimycin derivatives. }\end{array}$ & [63] \\
\hline 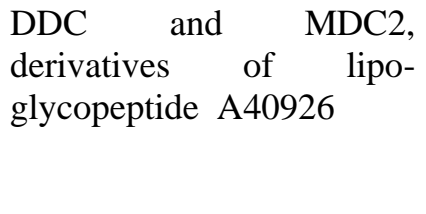 & Nonomuraea sp. & $\begin{array}{l}\text { Mutagenesis and selection } \\
\text { techniques improved the } \\
\text { antibiotic activity against } \\
\text { coagulase-negative } \\
\text { staphylococcus strains. }\end{array}$ & [69] \\
\hline Asenjonamides A-C & Streptomyces asenjonii & $\begin{array}{l}\text { Broth fermentation of the strain } \\
\text { isolated from extreme soil. }\end{array}$ & [70] \\
\hline Cyclohexylgriselimycin & Streptomyces sp. & $\begin{array}{l}\text { Resistance gene-based mining, } \\
\text { activating a copy of the dnaN } \\
\text { gene that potentiates the } \\
\text { activity of gryselimycin. }\end{array}$ & [71] \\
\hline Unknow & Streptomyces $s p$. & $\begin{array}{l}\text { Activation of cryptic genes to } \\
\text { acquire rifampicin resistance; } \\
\text { an unknown compound } \\
\text { belonging to a PKS was } \\
\text { generated. }\end{array}$ & [72] \\
\hline Unknow & Rhodococcus & $\begin{array}{l}\text { Genomic comparison to find } \\
\text { BGC; a PKS-I encoding an } \\
\text { antibiotic against } R \text {. equi }\end{array}$ & [73] \\
\hline Funisamin & Streptosporangium sp. & \begin{tabular}{lc} 
Mixed & \multicolumn{2}{c}{ culture-induced } \\
stimulation with Bacillus sp. \\
strains to produce a novel \\
PKS-type \\
antibiotic.
\end{tabular} & [74] \\
\hline
\end{tabular}

Genomic mining approaches mediated by genome sequencing methods, metabolic profiling, and using bioinformatics tools are an alternative capable of eliminating/inactivating/mutating cryptic biosynthetic genes and identifying new natural compounds.

\section{Conclusions}

In the face of demand for new drug therapies, microbial biosynthetic diversity studies have been of great help, and microbial genomes have revealed enormous reservoirs of natural products that remain unexplored. The current advantage of genome sequencing is the decrease in cost, technological advances in sequencing techniques, and bioinformatics growth; this has revealed many microorganisms' ability to produce secondary metabolites of pharmacological interest. Work to exploit genome sequences has led to the induction and expression of genes to detect novel molecules.

Low-invasive techniques to induce gene activation and more invasive techniques, such as heterologous expression and refactoring of gene clusters, prove that molecular biology, bacterial genetics, and synthetic biology are essential for discovering new natural products. Significant 
Natural products in Actinobacteria

advances in recent years have facilitated the identification and analysis of the structural diversity of bacterial products.

The new challenge is to develop heterologous expression strategies that are universally applicable and streamline studies of the expression of cryptic or silent genes present in most bacteria and are the source of novel chemical structures. By integrating knowledge from ecology, analysis of "omics" disciplines, and computational genomics, understanding bacterial metabolism could be within reach.

The search for secondary metabolites focuses on the study of target species that are useful in the isolation of new natural products; actinobacteria are essential sources of numerous products of interest and are considered bacteria with the potential to produce a wide range of new compounds, their study should be extended to "rare" genera that can produce structural biodiversity.

Advancing technology and science can enable important aspects: understanding the causes and ecology of genetic differences between closely related organisms; understanding similarities in unrelated organisms, whether some environments or communities select to produce specific secondary metabolites; knowing the external selective factors that bacteria need to create an arsenal of natural compounds; and knowing the role of natural compounds in the ecology to be secreted by bacteria.

\section{Acknowledgments}

This work was partially supported by National Council of Science and Technology of Mexico (CONACyT) through a postgraduate scholarship.

\section{ORCID}

Janette Berenice González-Nava: 0000-0002-6134-9252

Scarlett Alonso-Carmona: 0000-0002-7991-7246

Gauddy Lizeth Manzanares-Leal: 0000-0002-4517-2661

Horacio Sandoval-Trujillo: 0000-0002-7762-1775

Ninfa Ramírez Durán: 0000-0003-3108-895X

\section{References}

[1] J.S. Milshteyn, Schneider and S.F. Brady (2014). Mining the metabiome: identifying novel natural products from microbial communities, Chem. Biol. 21, 1211-1223.

[2] E.A Barka, P. Vatsa, L. Sanchez, N. Gaveau-Vaillant, C. Jacquard, J.P. Meier-Kolthoff, H.P. Klenk, C. Clément, Y. Ouhdouch and G.P. Van-Wezel (2016). Taxonomy, physiology, and natural products of actinobacteria, Microbiol. Mol. Biol. Rev. 25, 1-43.

[3] D.J. Newman and G. M. Cragg (2016). Natural products as sources of new drugs from 1981 to 2014, J. Nat. Prod. 25, 629-661.

[4] X. Guo, N. Liu, X. Li, Y. Ding, F. Shang, Y. Gao, J. Ruan and Y. Huang (2015). Red soils harbor diverse culturable actinomycetes that are promising sources of novel secondary metabolites, Appl. Environ. Microbiol. 1, 3086-3103.

[5] R. Subramani and D. Sipkema (2019). Marine rare actinomycetes: a promising source of structurally diverse and unique novel natural products, Marine Drug. 17, 249.

[6] L. Ouchari, A. Boukeskasse, B. Bouizgarne and Y. Ouhdouch (2019). Antimicrobial potential of actinomycetes isolated from the unexplored hot Merzouga desert and their taxonomic diversity, Biol. Open. 4, bio035410.

[7] C. Arango, A. Acosta-Gonzalez, C.M. Parra-Giraldo, Z.A. Sánchez-Quitian, R. Kerr and L.E. Díaz (2018). Characterization of actinobacterial communities from Arauca River sediments (Colombia) reveals antimicrobial potential presented in low abundant isolates, Open Microbiol. J. 31, 181-194.

[8] H. Lee, Y.K. Cheah, S. Mohd-Sidik, N.S. Ab-Mutalib, Y.L. Tang, H.P. Lin and K. Hong (2012). Molecular characterization of Antarctic actinobacteria and screening for antimicrobial metabolite production, World $J$. Microbiol. Biotechnol. 28, 2125-2137. 
[9] L. Shivlata and S. Tulasi (2015). Thermophilic and alkaliphilic actinobacteria: biology and potential applications, Front. Microbiol. 6, 1014.

[10] S.W. Behie, B. Bonet, V.M. Zacharia, D.J. McClung and M.F. Traxler (2017). Molecules to ecosystems: actinomycete natural products in situ, Front. Microbiol. 17, 2149.

[11] E.S. Fahal, A.M.E. Mahgoubel, Hassan and M.E. Abdel-Rahman (2015). Mycetoma in the Sudan: an update from the Mycetoma Research Centre, University of Khartoum, Sudan, PLoS Negl. Trop. Dis. 27, e0003679.

[12] J.B. González-Nava, K. Sánchez-Herrera, N. Ramírez-Durán and H. Sandoval (2016). First case of isolation of Nocardia wallacei reported in Mexico, New Microb. New Infect. 14, 83-84.

[13] S.A. Waksman and H.B. Woodruff (1940). Bacteriostatic and bactericidal substances produced by a soil actinomices, Proc. Soc. Exp. Biol. Med. 45, 609.

[14] S.D. Bentley, K.F. Chater, A.M. Cerdeño-Tárraga, G.L. Challis, N.R. Thomson, K.D. James, D.E. Harris, M.A. Quail, H.Kieser, D. Harper, A. Bateman, S. Brown, G. Chandra, C.W. Chen, M. Collins, A. Cronin, A. Fraser, A. Goble, J. Hidalgo, T. Hornsby, S. Howarth, C.H. Huang, T. Kieser, L. Larke, L. Murphy, K. Oliver, S. O'Neil, E. Rabbinowitsch, M.A. Rajandream, K. Rutherford, S. Rutter, K. Seeger, D. Saunders, S. Sharp, R. Squares, S. Squares, K. Taylor, T. Warren, A. Wietzorrek, J. Woodward, B.G. Barrell, J. Parkhill and D.A. Hopwood (2002). Complete genome sequence of the model actinomycete Streptomyces coelicolor A3(2), Nature 9, 141-47.

[15] M. Liu, Y. Jia, Y. Xie, C. Zhang, J. Ma, C. Sun and J. Ju (2019). Identification of the actinomycin D biosynthetic pathway from marine-derived Streptomyces costaricanus SCSIO ZS0073, Marine Drug. 17, 240.

[16] H. Jørgensen, E. Fjaervik, S. Hakvåg, P. Bruheim, H. Bredholt, G. Klinkenberg, T.E. Ellingsen and S.B. Zotchev (2009). Candicidin biosynthesis gene cluster is widely distributed among Streptomyces spp. isolated from the sediments and the neuston layer of the Trondheim fjord, Norway. Appl. Environ. Microbiol. 75, 3296-3303.

[17] D.R. Braun, M.G. Chevrette, D.D. Acharya, C.R. Currie, S.R. Rajski and T.S. Bugni (2018). Draft genome sequence of Micromonospora sp. strain WMMA1996, a marine sponge-associated bacterium, Genome Announ. 6, 18.

[18] K. Karničar, I. Drobnak, M. Petek, V. Magdevska, J. Horvat, R. Vidmar, Š Baebler, A. Rotter, P. Jamnik, Š Fujs, B. Turk, M. Fonovič, K. Gruden, G. Kosec and H. Petković (2016). Integrated omics approaches provide strategies for rapid erythromycin yield increase in Saccharopolyspora erythraea, Microb.l Cell Fact. 15, 93.

[19] J.M. Davidsen and C.A. Townsend (2012). In vivo characterization of nonribosomal peptide synthetases NocA and NocB in the biosynthesis of nocardicin A, Chem. Biol. 19, 297-306.

[20] K. Komatsu, M. Tsuda, M. Shiro, Y. Tanaka, Y. Mikami and J. Kobayashi (2004). Brasilicardins B-D, new tricyclic terpenoids from actinomycete Nocardia brasiliensis, Bioorg. Med. Chem. 12, 5545-5551.

[21] Y. Hoshino, K. Chiba, K. Ishino, T. Fukai, Y. Igarashi, K. Yazawa, Y. Mikami and J. Ishikawa (2011). Identification of nocobactin NA biosynthetic gene clusters in Nocardia farcinica, J. Bacteriol. 193, 441448.

[22] S. Kokubo, K. Suenaga, C. Shinohara, T. Tsuji and D. Uemura (2000). Structures of amamistatins A and B, novel growth inhibitors of human tumor cell lines from Nocardia asteroides, Tetrahedron 56, 64356440.

[23] K. Sakai, H. Komaki and T. Gonoi (2015). Identification and functional analysis of the nocardithiocin gene cluster in Nocardia pseudobrasiliensis, PloS one 10, e0143264.

[24] Y. Gao, G. Xu, P. Wu, J. Liu, Y.S. Cai, Z. Deng and W. Chen (2017). Biosynthesis of 2'chloropentostatin and 2'-amino-2'-deoxyadenosine highlights a single gene cluster responsible for two independent pathways in Actinomadura sp. strain ATCC 39365, Appl. Environ. Microbiol. 83, e0007817.

[25] H. Komaki, E. Harunari, N. Ichikawa, A. Hosoyama, M. Hamada, K. Duangmal, A. Thamchaipenet and Y. Igarashi (2020). Draft genome sequence of Actinomadura sp. K4S16 and elucidation of the nonthmicin biosynthetic pathway, J. Genomics 8, 53-61. 
Natural products in Actinobacteria

[26] D. Garrido-Sanz, P. Sansegundo-Lobato, M. Redondo-Nieto, J. Suman, T. Cajthaml, E. Blanco-Romero, M. Martin, O. Uhlik and R. Rivilla (2020). Analysis of the biodegradative and adaptive potential of the novel polychlorinated biphenyl degrader Rhodococcus sp. WAY2 revealed by its complete genome sequence, Microb. Genomics. 6, e000363.

[27] K. Passari, V.K. Mishra, G. Singh, P. Singh, B. Kumar, V.K. Gupta, R.K. Sarma, R. Saikia, A.O. Donovan and B.P. Singh (2017). Insights into the functionality of endophytic actinobacteria with a focus on their biosynthetic potential and secondary metabolites production, Sci. Rep. 7, 11809.

[28] D. Schwarzer and M.A. Marahiel (2001). Multimodular biocatalysts for natural product assembly, Naturwissenschaften 88, 93-101.

[29] H. Wang, D.P. Fewer, L. Holm, L. Rouhiainen and K. Sivonen (2014). Atlas of nonribosomal peptide and polyketide biosynthetic pathways reveals common occurrence of nonmodular enzymes, Proc. Natl. Acad. Sci. 111, 9259-9264.

[30] J. Staunton and B. Wilkinson (2001). Combinatorial biosynthesis of polyketides and nonribosomal peptides, Curr. Opin. Chem. Biol. 5, 159-164.

[31] D.W. Christianson (2017). Structural and chemical biology of terpenoid cyclases, Chem. Rev. 117, 11570-11648.

[32] G.K. Reddy, N. Leferink, M. Umemura, S.T. Ahmed, R. Breitling, N.S. Scrutton and E. Takano (2020). Exploring novel bacterial terpene synthases, PloSone 15, e0232220.

[33] A.H. Russell and A.W. Truman (2020). Genome mining strategies for ribosomally synthesised and posttranslationally modified peptides, Comput. Struct. Biotech.. 18, 1838-1851.

[34] P.G. Arnison, M.J. Bibb, G. Bierbaum, A.A. Bowers, T.S. Bugni, G. Bulaj, J.A. Camarero, D.J. Campopiano, G.L. Challis, J. Clardy, P.D. Cotter, D.J. Craik, M. Dawson, E. Dittmann, S. Donadio, P.C. Dorrestein, K.D. Entian, M.A. Fischbach, J.S. Garavelli, U. Göransson, C.W. Gruber, D. H. Haft, T. K. Hemscheidt, C. Hertweck, C. Hill, A. R. Horswill, M. Jaspars, W. L. Kelly, J. P. Klinman, O. P. Kuipers, A. J. Link, W. Liu, M.A. Marahiel, D. A. Mitchell, G. N. Moll, B.S. Moore, R. Müller, S.K Nair, I. F. Nes, G. E. Norris, B.M. Olivera, H. Onaka, M.L. Patchett, J. Piel, M. J. T. Reaney, S. Rebuffat, R. P. Ross, H.G. Sahl, E. W. Schmidt, M. E. Selsted, K. Severinov, B. Shen, K. Sivonen, L. Smith, T. Stein, R. D. Süssmuth, J.R. Tagg, G.L. Tang, A.W. Truman, J.C. Vederas, C. T. Walsh, J.D. Walton, S.C Wenzel, J.M. Willey, W. A. van der Donk (2013). Ribosomally synthesized and post-translationally modified peptide natural products: overview and recommendations for a universal nomenclatura, Nat. Prod. Rep. 30, 108-160.

[35] M.A. Ortega and W.A. van der Donk (2016). New insights into the biosynthetic logic of ribosomally synthesized and post-translationally modified peptide natural products, Cell. Chem. Biol. 23, 31-44.

[36] P. Cimermancic, M.H. Medema, J. Claesen, K. Kurita, L.C. Wieland-Brown, K. Mavrommatis, A. Pati, P.A. Godfrey, M. Koehrsen, J. Clardy, B.W. Birren, E. Takano, A. Sali, R.G. Linington and M.A. Fischbach (2014). Insights into secondary metabolism from a global analysis of prokaryotic biosynthetic gene clusters, Cell 158, 412-421.

[37] E.S. Gomes, V. Schuch and E.G. de Macedo Lemos (2014). Biotechnology of polyketides: new breath of life for the novel antibiotic genetic pathways discovery through metagenomics, Braz. J. Microbiol. 44, 1007-1034.

[38] K. Blin, S. Shaw, K. Steinke, R. Villebro, N. Ziemert, S.Y. Lee, M.H. Medema and T. Weber (2019). antiSMASH 5.0: updates to the secondary metabolite genome mining pipeline, Nucleic Acids. Res. 47, W81-W87.

[39] T. Weber (2014). In silico tools for the analysis of antibiotic biosynthetic pathways, Int. J. Med. Microbiol. 304, 230-235.

[40] M.H. Li, P.M. Ung, J. Zajkowski, S. Garneau-Tsodikova and D.H. Sherman (2009). Automated genome mining for natural products, BMC Bioinform. 10, 185.

[41] J. Starcevic, J. Zucko, P.F. Simunkovic, J. Long, and D. Hranueli (2008). ClustScan: an integrated program package for the semi-automatic annotation of modular biosynthetic gene clusters and in silico prediction of novel chemical structures, Nucleic Acid. Res. 36, 6882-6892.

[42] M.H. Medema, E. Takano and R. Breitling (2013). Detecting sequence homology at the gene cluster level with MultiGeneBlast, Mol. Biol. Evol. 30, 1218-1223. 
[43] S.A. Kautsar, K. Blin, S. Shaw, J.C. Navarro-Muñoz, B.R. Terlouw, J. van der Hooft, J.A. van Santen, V. Tracanna, H.G. Suarez-Duran, V. Pascal-Andreu, N. Selem-Mojica, M. Alanjary, S.L. Robinson, G. Lund, S.C. Epstein, A.C. Sisto, L.K. Charkoudian, J. Collemare, R.G. Linington, T. Weber, and M.H.Medema (2020). MIBiG 2.0: a repository for biosynthetic gene clusters of known function, Nucleic Acid Res. 48, D454-D458.

[44] N. Ichikawa, M. Sasagawa, M. Yamamoto, H. Komaki, Y. Yoshida, S. Yamazaki and N. Fujita (2013). DoBISCUIT: a database of secondary metabolite biosynthetic gene clusters, Nucleic Acid. Res. 41, D408D414.

[45] K.R. Conway and C.N. Boddy (2013). ClusterMine360: a database of microbial PKS/ NRPS biosynthesis, Nucleic Acid. Res. 41, D402-D407.

[46] J. Hastings, G. Owen, A. Dekker, M. Ennis, N. Kale, V. Muthukrishnan, S. Turner, N. Swainston, P. Mendes and C. Steinbeck (2016). ChEBI in 2016: Improved services and an expanding collection of metabolites, Nucleic Acid. Res. 44, D1214-D1219.

[47] D. Mendez, A. Gaulton, A.P. Bento, J. Chambers, M. De Veij, E. Félix, M.P. Magariños, J.F. Mosquera, P. Mutowo, M. Nowotka, M. Gordillo-Marañón, F. Hunter, L. Junco, G. Mugumbate, M. RodriguezLopez, F. Atkinson, N. Bosc, C.J. Radoux, A. Segura-Cabrera, A. Hersey and A.R. Leach (2019). ChEMBL: towards direct deposition of bioassay data, Nucleic Acid. Res. 47, D930-D940.

[48] Y. Nakamura, F.M. Afendi, A.K. Parvin, N. Ono, K. Tanaka, A. Hirai Morita, T. Sato, T. Sugiura, M. Altaf-Ul-Amin and S. Kanaya (2014). KNApSAcK metabolite activity database for retrieving the relationships between metabolites and biological activities, Plant Cell Physiol. 55, e7.

[49] M. Röttig, M.H. Medema, K. Blin, T. Weber, C. Rausch and O. Kohlbacher (2011). NRPSpredictor2-a web server for predicting NRPS adenylation domain specificity, Nucleic Acid. Res. 39 W362-W367.

[50] E. Flissi, C. Ricart, M. Campart, Y. Chevalier, J. Dufresne, P. Michalik, C. Jacques, F. Flahaut, V. Lisacek, Leclère and M. Pupin (2020). Norine: update of the nonribosomal peptide resource, Nucleic Acid. Res. 48, D465-D469.

[51] M. Moumbock, A Gao, J. Qaseem, P.A. Li, B. Kirchner, B.D Ndingkokhar, C.V. Bekono, S.B. Simoben, Y.I. Babiaka, F. Malange, P. Sauter, F. Zierep, Ntie-Kang and S. Günther (2021). StreptomeDB 3.0: an updated compendium of streptomycetes natural products, Nucleic Acid. Res. 49, D600-D604.

[52] M.H. Medema and M.A. Fischbach (2015). Computational approaches to natural product Discovery, Nat. Chem. Biol. 11, 639.

[53] M. Poulsen, D.C. Oh, J. Clardy and C.R. Currie (2011). Chemical analyses of wasp-associated streptomyces bacteria reveal a prolific potential for natural products Discovery, PLoSone. 6, e16763.

[54] Y. Tanaka, T. Hosaka and K. Ochi (2010). Rare earth elements activate the secondary metabolitebiosynthetic gene clusters in Streptomyces coelicolor A3(2), J. Antibiot. 63, 477-481.

[55] H. Onaka, Y. Mori, Y. Igarashi and T. Furumai (2011). Mycolic acid-containing bacteria induce naturalproduct biosynthesis in Streptomyces species, Appl. Environ. Microbiol. 77, 400-06.

[56] R. Bunet, L. Song, M.V. Mendes, C. Corre, L. Hotel, N. Rouhier, X. Framboisier, P. Leblond, G.L. Challis and B. Aigle (2011). Characterization and manipulation of the pathway-specific late regulator AlpW reveals Streptomyces ambofaciens as a new producer of Kinamycins, J. Bacteriol. 193,1142-1153.

[57] S. Aigle, D. Lautru, J.S Spiteller, G.L Dickschat, P. Challis, Leblond and J.L. Pernodet (2014). Genome mining of Streptomyces ambofaciens, J. Ind. Micbiol. Bio. 41, 251-263.

[58] S. Männle, S.S. McKinnie, K. Mantri, Z. Steinke, B.S. Lu, N. Moore, Ziemert and L. Kaysser (2020). Comparative genomics and metabolomics in the genus Nocardia, mSystems 5, e00125-20.

[59] X. Tang, J. Li, N. Millán-Aguiñaga, J.J. Zhang, E.C. O'Neill, J.A. Ugalde, P.R. Jensen, S.M. Mantovani and S. Moore (2015). Identification of thiotetronic acid antibiotic biosynthetic pathways by targetdirected genome mining. ACS Chem. Biol. 10, 2841-2849.

[60] N. Ziemert, M. Alanjary and T. Weber (2016). The evolution of genome mining in microbes-a review, Nat. Prod. Rep. 33, 988-1005.

[61] L. Laureti, L. Song, S. Huang, C. Corre, P. Leblond, G.L. Challis and B. Aigle (2011). Identification of a bioactive 51-membered macrolide complex by activation of a silent polyketide synthase in Streptomyces ambofaciens, Proc. Natl. Acad. Sci. 108, 6258-6263. 
[62] R. Mishra, D. Dhakal, J.M. Han, H.N. Lim, H.J. Jung, T. Yamaguchi and J.K. Sohng (2019). Production of a novel tetrahydroxynaphthalene (THN) derivative from Nocardia sp. CS682 by metabolic engineering and its bioactivities, Molecules 24, 244.

[63] T. Awakawa, T. Fujioka, L. Zhang, S. Hoshino, Z. Hu, J. Hashimoto, I. Kozone, H. Ikeda, K. Shin-Ya, W. Liu and I. Abe (2018). Reprogramming of the antimycin NRPS-PKS assembly lines inspired by gene evolution, Nature Commun. 9, 3534.

[64] L. Mitousis, Y. Thoma and E.M. Musiol-Kroll (2020). An update on molecular tools for genetic engineering of actinomycetes-the source of important antibiotics and other valuable compounds, Antibiotics 8, 494.

[65] J. Wang, A. Lu, J. Liu, W. Huang, J. Wang, Z. Cai and G. Zhao (2019). iCatch: a new strategy for capturing large DNA fragments using homing endonucleases, Acta Biochim. Biophys. Sin. (Shanghai), 51,97-103.

[66] E.R. Greunke, P.M. Duell, A. D'Agostino, K. Glöckle, Lamm and T.A.M. Gulder (2018). Direct pathway cloning (DiPaC) to unlock natural product biosynthetic potential, Metab. Eng. 47, 334-345.

[67] S. Ye, B. Enghiad, H. Zhao and E. Takano (2020). Fine-tuning the regulation of Cas9 expression levels for efficient CRISPR-Cas9 mediated recombination in Streptomyces, J. Ind. Microbiol. Biot. 47, 413423.

[68] L. Li, Y. Zhao, L. Ruan, S. Yang, M. Ge, W. Jiang and Y. Lu (2015). A stepwise increase in pristinamycin II biosynthesis by Streptomyces pristinaespiralis through combinatorial metabolic engineering, Metab. Eng. 29, 12-25.

[69] A. Beltrametti, C. Lazzarini, A. Brunati, S. Marazzi, E. Jovetic, Selva and F. Marinelli (2003). Production and characterization of monochlorinated and dechlorinated A40926 derivatives, J. Antibiot. 56, 773-782.

[70] M.S.A. Abdelkader, T. Philippon, J.A. Asenjo, A.T. Bull, M. Goodfellow, R. Ebel, M. Jaspars and M.E. Rateb (2018). Asenjonamides A-C, antibacterial metabolites isolated from Streptomyces asenjonii strain KNN42.f from an extremehyper arid Atacama Desert soil, J. Antibiot. 71, 425-431.

[71] P. Kling, D.V. Lukat, A. Almeida, E. Bauer, S. Fontaine, Sordello, et al (2015). Targeting DnaN for tuberculosis therapy using novel griselimycins, Science 348,1106-1112.

[72] W.L. Thong, K. Shin-ya, M. Nishiyama and T. Kuzuyama (2016). Methylbenzene-containing polyketides from a Streptomyces that spontaneously acquired rifampicin resistance: Structural elucidation and biosynthesis, J. Nat. Prod. 79, 857-864.

[73] A.L. Ward, P. Reddyvari, R. Borisova, A.G. Shilabin and B. C. Lampson (2018). An inhibitory compound produced by a soil isolate of Rhodococcus has strong activity against the veterinary pathogen R. equi, PloS one. 13, e0209275.

[74] B.C. Covington, J.M. Spraggins, A.E. Ynigez-Gutierrez, Z.B. Hylton and B.O. Bachmann (2018). Response of secondary metabolism of hypogean actinobacterial genera to chemical and biological stimuli, Appl. Environ. Microbiol. 84, e01125-18.

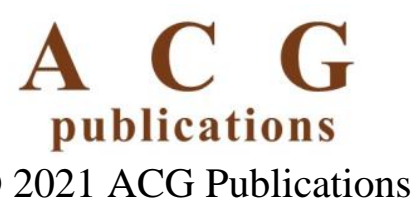

